\title{
OBJETOS DA MEMÓRIA EM “DEPOIS DE AUSCHWITZ” DE EVA SCHLOSS
}

\author{
GABRIELA GOMES DE OLIVEIRA \\ Universidade Federal de Minas Gerais \\ gabrielagomes.deoliveira@outlook.com
}

RESUMO

A Segunda Guerra Mundial é um tema bastante recorrente que desperta grande fascínio nas diversas áreas do conhecimento. Várias obras que foram publicadas com o intuito de testemunhar os horrores do Holocausto alcançaram grande êxito, uma vez que narrar o inimaginável parece causar grande impacto nos leitores. Quando Eva Schloss decide publicar a obra "Depois de Auschwitz" ela parece querer evocar, ao mesmo tempo, sentimentos como tristeza e esperança. O primeiro, obviamente, reflete o abalo sofrido em consequência da perseguição dos nazistas. $\mathrm{O}$ segundo, por sua vez, emerge como a vontade de sobreviver em meio à desordem. Tomando como ponto de reflexão os objetos pessoais de milhares de prisioneiros do campo de concentração Auschwitz-Birkenau, este artigo pretende compreender qual a importância desses itens - aglomerados em vários armazéns do campo - com as relações memorialísticas que eles sugerem. Para tanto, contaremos com o apoio teórico de Maria Esther Maciel (2004), Giorgio Agamben (2008) e Vera Casa Nova (2014).

PALAVRAS-CHAVE: Eva Schloss, testemunho, objetos, memoria.

\section{OBJECTS OF MEMORY IN "AFTER AUSCHWITZ", BY EVA SCHLOSS}

\section{ABSTRACT}

The Second World War is a recurring theme that arouses great fascination in the various areas of knowledge. Several works that were published to witness the horrors of the Holocaust were very successful, since narrating the unimaginable seems to have great impact on readers. When Eva Schloss decides to publish the work "After Auschwitz" she seems to want to evoke, at the same time, feelings like sadness and hope. The first, obviously, reflects the shock suffered as a result of the persecution of the Nazis. The second, in turn, emerges as the will to survive amid the disorder. Taking as a point of reflection the personal objects of thousands of prisoners in the Auschwitz-Birkenau concentration camp, this article intends to understand the importance of these items - clustered in various warehouses in the countryside - with the memorialistic relations they suggest. We will have the theoretical support of Maria Esther Maciel (2004), Giorgio Agamben (2008) and Vera Casa Nova (2014).

KEYWORDS: Eva Schloss, witness, objects, memory.

A Segunda Guerra Mundial foi um fenômeno histórico que reverbera seus sons e imagens ainda nos dias de hoje. As consequências a posteriori, de um regime autoritário e perseguidor, são rememoradas e sentidas não apenas por aqueles que experienciaram o horror, mas também por todos os que entendem que a liberdade e os direitos humanos devem ser a pauta do mundo moderno. Muito 
se foi dito e escrito acerca dos acontecimentos desde a ascensão de Adolf Hitler, em 1933, até o fim da guerra em 1945. Seria uma tarefa árdua retomar ou tentar esclarecer fatos daquele período, constantemente debatidos e estudados mundo afora. "Depois de Auschwitz", entretanto, surge como uma obra que acordou o interesse em alguns aspectos dessa época que merecem certa atenção: memória e coisas.

Eva Schloss nasceu em Viena, na Áustria, em 11 de maio de 1929 e é uma sobrevivente. Judia. Sua infância tranquila no seio da família, composta por sua mãe Fritzi Geiringer (Mutti), seu pai Erich Geiringer (Pappy) e seu irmão mais velho Heinz Geiringer, se desestruturou completamente - e definitivamente - no momento em que judeus de toda a Europa começaram a ser discriminados e perseguidos durante o regime nazista. A pequena Eva viveu parte de sua juventude em Amsterdã, especificamente em Merwedeplein, local bastante conhecido por causa dos escritos do diário de Anne Frank. As duas garotas, inclusive, chegaram a se conhecer e Eva já admitiu sentir, àquela época, uma grande admiração por sua vizinha que "atraía muitas pessoas ao contar histórias engraçadas".

Com o passar do tempo, e com o aumento sistemático da repressão e da violência contra o povo judeu, a família Geiringer se separou e passou a viver em esconderijos. Eva e sua mãe ficaram juntas, enquanto seu irmão ficou aos cuidados do pai. Com a perda da infância e das alegrias e despreocupações de uma vida comum, restou à família apenas a luta pela sobrevivência. Motivados por esses objetivos e desejosos de que a guerra alcance seu fim, conseguiram resistir por um tempo. Visitavam-se com frequência, mudando regularmente de abrigo a fim de evitar serem descobertos pelos oficiais da SS - em alemão Schutzstaffel, em português "Tropa de Proteção". Contudo, a vida comum nunca mais faria parte das expectativas dessa e de outras famílias que, como os Geiringer, foram denunciadas (por recompensas ou por ódio) e enviadas aos campos de concentração.

\section{Os Recantos da MEMÓRIA}

O livro "Depois de Auschwitz" foi publicado em português no ano de 2013. Trata-se da biografia da própria Eva Schloss que, ao invés de se calar diante das crueldades que sofreu, preferiu transformar em memória narrada aquilo que não se deve repetir. A obra conta 28 capítulos que narram episódios que vão desde sua tenra idade até os dias atuais. A autora, atualmente com 88 anos, escolheu como missão de vida ajudar jovens e adultos a compreender o quão perigoso é o preconceito. Em entrevista cedida este ano, Eva aponta semelhanças, infelizmente negativas, entre o mundo nazista e o atual. Ela afirma, com pesar, que "o mundo está vivendo um período de insegurança. Muito ódio, preconceito e conflitos ao mesmo tempo. Parece o tempo de Hitler. O ódio está fazendo com 
que tenhamos um clima parecido ao que existia nos anos 30, às vésperas da Segunda Guerra" (Chade 2018).

A afirmação acima poderia ser interpretada como exagerada por alguns, mas vinda de uma vítima e sobrevivente que vê o mundo de hoje com os mesmos olhos que viram os horrores do Holocausto, deveria ter alguma relevância ao refletirmos sobre nossas condições políticas e sociais. $\mathrm{O}$ próprio termo Holocausto carrega em si várias ressignificações que trazem à tona a importância de lutar contra o ódio supracitado. Conforme Agamben (2008: 37), "o infeliz termo "holocausto" (frequentemente com H maiúsculo) origina-se dessa inconsciente exigência de justificar a morte sine causa, de atribuir um sentido ao que parece não poder ter sentido [...]". O sem-sentido, o não-justificado são temas presentes em toda a obra.

Com o objetivo de lançar luz sobre as experiências do "holocausto" a partir da perspectiva das recordações de Eva Schloss, optou-se por trabalhar com dois capítulos que evidenciam e detalham sua passagem pelo campo de concentração Auschwitz-Birkenau. Em “Auschwitz-Birkenau" e "A vida no campo" parece possível apanhar um arcabouço memorialístico forte, que nos permita indagar se a história semântica do termo "holocausto", por si só, não seria um prelúdio daquilo que Eva posteriormente viveria. Segundo Agamben (2008: 37), essa palavra provém do latim holocaustum e, subsequente, do grego holókaustus "(um adjetivo que significa literalmente "todo queimado" [...]" e serviu de base para os padres da Igreja traduzirem sem qualquer rigor "a complexa doutrina sacrifical da Bíblia". Sendo assim, pode-se proferir a seguinte indagação: quantos sacrifícios humanos foram realizados sob o manto do termo "holocausto"? E para os sacrificados que ainda vivem, ou viveram nos anos seguintes, o que resta? A resposta, ou a pergunta que se segue seria: memória.

Para iniciar os relatos acerca da vida no campo de concentração, Eva recorreu ao primeiro instante, ao momento de partida. De uma partida sem retorno. Como se para buscar na memória aquilo que não mais existe - e nunca mais existirá - devesse se comportar como alguém que revira a terra para reencontrar algo há muito soterrado. A memória traz a dor, mas não o esquecimento. Conforme Casa Nova (2014: 67), para narrar o inenarrável, o "narrador sucateiro" deve recolher aquilo que aparentemente não tem sentido, "mas que deve ser transmitido e lembrado como transmissão simbólica". O "holocausto", a morte em forma de sacrifício por uma doutrina ditatorial, não faz sentido, mas não pode ser esquecido.

O trem nos levou lentamente, atravessando o continente europeu durante três dias e três noites. Estávamos na escuridão, presos como animais condenados, com um balde fedido para ser usado como banheiro e outro com água. Uma vez por dia, o trem parava e os guardas gritavam ao abrir as portas, cegando-nos com a luz do dia, e jogavam alguns pedaços de pão antes de o crepúsculo voltar a nos desorientar. (Schloss 2013: 98) 
A vida familiar em Merwedeplein deu lugar ao início da separação e da não-mais-vida. Talvez a única coisa que lhes restaria, o mínimo da dignidade que é a humanidade, lhes foi tirada no momento em que entraram nos vagões de gado lotados com destino a Auschwitz-Birkenau. A luz no fim do túnel, aquela que simboliza popularmente a esperança de algo melhor, agora os cegava. As normas que regem o mundo civilizado deixam de existir no instante em que se adentra aos portões e se depara com a conhecida frase "o trabalho liberta". Segundo Agamben (2008: 12), "com a experiência dos campos de concentração acontece uma devastadora ausência de normas; a administração nazista estabelece uma "ordem" tão rígida quanto aleatória, os presos são entregues a um arbítrio implacável". A definição de Auschwitz, feita por Eva, esclarece muito bem a noção de "ordem aleatória" de Agamben.

Tínhamos chegado a Auschwitz, um campo de extermínio do tamanho de uma pequena cidade, com milhares de trabalhadores ocupados, dedicados a aperfeiçoar o assassinato em massa e a extinção da raça judia. (Schloss 2013: 99)

Ter como profissão o extermínio de inocentes é algo assustador. Mas, possivelmente, rememorar o primeiro momento em um campo de concentração aparenta ser ainda mais atormentador. Procurar na memória aquela caixa que contém a dor, suas sensações e imagens, parece ser algo que extrapola as normas e que, pelo contrário, declara sua ausência. Ao chegar no campo, de acordo com Eva, os guardas da SS solicitavam aos recém-chegados que se desfizessem de todos os pertences que traziam consigo. As pessoas que já haviam sentido a falta de humanidade durante o transporte para o campo, agora perdiam aqueles objetos carregados de memória. Ela relata, ainda, que dos mais de 300 campos administrados pelos nazistas, aquele era o maior deles.

- Bem-vindas a Birkenau - elas diziam com sarcasmo enquanto nos empurravam e nos davam socos. - A sorte de vocês acaba de chegar ao fim. Podem sentir o cheiro dos crematórios? É lá que seus familiares receberam gás no que acreditavam serem salas de banho. Eles estão queimando agora. Vocês nunca voltarão a vê-los. (Schloss 2013: 105)

Conforme Casa Nova (2014: 70), Birkenau “guarda a memória: “um chão que berra"'". Um chão que testemunhou o pré-assassinato, ou seja, o assassinato primeiro da esperança - aquele que te abraça no momento em que o indivíduo percebe que não há mais volta. No primeiro contato com as Kapos, funcionárias do campo, Eva testemunha o sarcasmo e a falta de cuidado humano que rodeiam o dia a dia do local. Além, obviamente, da morte presente e latente. Essas funcionárias, aliás, eram incumbidas de raspar a cabeça das novatas e disciplinálas, caso cometessem algum erro no campo. Outros assassinatos, antes do derradeiro, ainda passaram pela vida de Eva. Após a perda dos cabelos e de todas as posses, agora via sua identidade reduzida a um número: “Mutti passou os braços por sobre meus ombros enquanto outra Kapo pegava uma agulha e uma 
garrafa de tinta para tatuar meu número no meu braço esquerdo" (Schloss 2013: 106).

Eu agora era a prisioneira A/5272 - parte de um processo cujo objetivo era acabar com meu orgulho e com minha identidade. Quando fui levada para fora da estação de trem de Auschwitz, deixei a menina Eva Geiringer e seus sonhos para trás. Tínhamos passado nossos últimos momentos juntos como uma família, e eu jamais voltaria a ver meu irmão. (Schloss 2013: 108)

Ter o próprio nome substituído por um número parece ter marcado toda a vida de Eva. O número tatuado não representaria, nesse testemunho, apenas o apagar de seu registro civil, mas de sua própria identidade. A menina austríaca, exilada em Amsterdã, agora era "a prisioneira A/5272" na Polônia invadida pelos alemães. O A/5272, ao mesmo tempo, emerge a perda do irmão, que morrerá de exaustão em Auschwitz. Uma menina de 15 anos, sem pátria, sem rosto, sem cabelos e sem seu maior pertence: seu nome. O principal de seu testemunho, isto é, sua essência, já não pode ser dito.

A testemunha comumente testemunha a favor da verdade e da justiça, e delas a sua palavra extrai consistência e plenitude. Nesse caso, porém, o testemunho vale essencialmente por aquilo que nele falta; contém, no seu centro, algo intestemunhável, que destitui a autoridade dos sobreviventes. As "verdadeiras" testemunhas, as "testemunhas integrais" são as que não testemunharam, nem teriam podido fazê-lo. (Agamben 2008: 43)

Por mais que Eva relate todas as suas memórias da época, e queira expor todos os horrores vividos para que não se repitam, o "intestemunhável" parece estar sempre presente. Heinz, seu irmão por quem ela declara um grande carinho, não está mais presente. Ele testemunhou até o fim os horrores do "holocausto" e, em função disso, por atravessar a linha de chegada, morreu. $\mathrm{O}$ testemunho vale como alerta, como memória, como história. Lhe faltará, porém, a parte completa, o que as vítimas "reais", ou seja, aquelas que caíram testemunhariam se ainda pudessem falar. Poder exteriorizar através do papel lembranças tão fortes sugere que Eva, mesmo não sendo uma "testemunha integral", faria parte do grupo das testemunhas da não-vida. Uma vida cruel e sem volta, mas que merece ser contada. A existência de alguém que lutou pela vida em um local onde esse conceito caiu em desuso, e que luta ainda hoje para que outras vidas não entrem novamente pelos portões dos campos de extermínio. "Nem todo mundo conseguia se adaptar. As pessoas que não se ajustavam à vida no campo viviam com um olhar vago, perdiam as esperanças e morriam" (Schloss 2013: 109).

Os vales da memória que figuram em "Depois de Auschwitz" parecem querer resgatar os momentos tristes vividos por Eva e sua família, mas também apontam para uma esperança escondida em cada um; que ressuscita naqueles que ainda possuem alguma força para lutar. Segundo Casa Nova (2014: 69), “se as pequenas coisas lá escavadas estão silenciosas, as palavras fazem ressurgir o 
movimento da emoção [...]". As memórias escavadas por Eva revelam essa "testemunha da não-vida", mas também de pequenos gestos positivos que fazem reacender a chama da sobrevivência possível. "À minha volta, Birkenau fervilhava com dezenas de milhares de pessoas, todas elas tentando aguentar e prolongar uma existência nas mais difíceis condições que se pode imaginar" (Schloss 2013: 107).

Trata-se de uma reflexão convergente sobre a memória traumática, sobre a experiência de choque. Ver através dos rastros o inimaginável. Narrar o impossível, o inimaginável? Eis o desafio: "nunca apagar os rastros", "nunca deixar cair no esquecimento", narrar as ruínas pela palavra, pela imagem. (Casa Nova 2014: 67)

A memória traumática é algo que permeia todo o texto de Eva, como se a menina de 15 anos estivesse encarando, ainda hoje, os rostos daquelas várias pessoas que lutaram por sua existência. Como narrar o inimaginável? É de suma importância não deixar suas memórias e seu testemunho caírem no esquecimento e o texto literário surge como plataforma de disseminação das recordações - dolorosas. Entretanto, pode-se pensar, como o fez Casa Nova, que o desafio de narrar as ruínas possa ser realizado pela palavra e pela imagem. Propõe-se a partir daqui uma terceira reflexão: narrar a memória também através dos objetos.

\section{OS OBJETOS NA MEMÓRIA}

Um dos objetos essenciais para a sobrevivência em Auschwitz era a caneca que se recebia no momento em que se chegava ao campo. Na falta desse item, lhe faltaria a comida rala, servida como a animais. "Quando recebi minha caneca, amarrei-a às minhas roupas surradas e nunca a deixei fora da minha vista" (Schloss 2013: 109). Se, por um lado, os prisioneiros não tinham direito a nada, por outro, perdia-se o "direito" de se alimentar com a ausência desse utensílio básico. A caneca amarrada aos trapos de Eva poderia ser apreendida como o único objeto que lhe restara, como o último bem pessoal em meio ao caos. Todavia, havia outros bens, muito mais valiosos que, fora do alcance de seus donos, amontoavam-se em montanhas de deslembranças.

O tal "direito a sobrevivência" também estava diretamente ligado às tarefas executadas no campo de concentração. Caso um prisioneiro tivesse a sorte a seu lado, conseguiria um posto elevado de trabalho em escritórios, cozinhas ou hospitais. Outros, entretanto, não gozariam do mesmo destino, sendo enviados a trabalhar com a terra ou tomando medidas cruéis contra outros prisioneiros. "Birkenau tinha uma equipe de Sonderkommandos - prisioneiros que trabalhavam nas câmaras de gás, buscando as últimas posses, arrancando dentes de ouro e despindo os corpos" (Schloss 2013: 111). A morte indicaria o fim de seus últimos traços de dignidade. Seu corpo seria invadido e, como se não bastassem os bens 
saqueados no início da não-vida no campo, o seu fim anunciaria o rapto dos únicos itens que ainda lhe restavam.

A maioria de nós recebia ordens para realizar diferentes tipos de trabalhos manuais, fosse lavando roupa, fazendo parte de uma unidade externa de trabalho para produzir munições alemãs ou trabalhando nos armazéns, separando infinitas pilhas de roupas e pertences tomados daqueles que chegavam nos trens. (Schloss 2013: 112)

O trabalho árduo era a rotina dos prisioneiros. Eva teve sorte; conseguiu trabalhar em um local privilegiado do campo e levou consigo sua mãe. "Eu sabia que "Canadá" era a mais valorizada de todas as unidades de trabalho" (Schloss 2013: 115). Como a autora relata, o "Canadá" era a "terra da plenitude", "uma vasta área atrás do campo onde enormes pilhas de posses dos prisioneiros esperavam para serem separadas e classificadas" (Schloss 2013: 115). As coisas lá existentes possuíam um nome, uma característica que as descrevesse. Mas em circunstâncias como aquela, "as pilhas de posses" perderiam, talvez, a identidade que as definia na vida longe do campo. Assim como ocorreu com quem as portava anteriormente.

Da palavra "coisa" emergem várias possibilidades de sentido. Se, num extremo, ela é capaz de designar tudo quanto existe ou possa existir para ser nomeado, classificado, definido ou representado, no outro aponta para o que não se sabe, para o enigma do que resiste aos nomes e à classificação. (Maciel 2004: 97)

A palavra "coisa", aqui pertencente ao mesmo grupo da palavra "objeto", parece perder sua classificação e suas várias significações a partir do momento em que é transportada para uma realidade sem normas. Ela é tão viva que escancara abertamente os desafios a serem enfrentados sob o comando nazista. Olha-se para uma caneca, objeto palpável, e tem-se a sensação de que nada ali é real. No mundo lá fora, esse objeto não seria utilizado nessas condições. Poucos sobrevivem a essas situações, nada resiste sob tais circunstâncias, tampouco as coisas. "Trata-se de fatos tão reais que, comparativamente, nada é mais verdadeiro; uma realidade que excede necessariamente os seus elementos factuais [...]" (Agamben 2008: 20). Eva deparou-se, ao entrar pela primeira vez no "Canadá", com grandes montanhas de objetos, que pela sua impossibilidade de transparecer a vida, parecem estar mortos.

O Canadá parecia uma terra sombria de maravilhas, repleta de surpresas. Aproximei-me de uma enorme pilha de metal que brilhava sob a luz do sol e me dei conta, espantada, de que ela era composta por milhares de pares de óculos. Um armazém estava cheio de edredons até o teto, ao passo que outro não continha nada além de braços e pernas falsas. Havia milhares e milhares de sapatos, malas e baús de todos os tamanhos e formas. (Schloss 2013: 115)

A realidade das coisas. Óculos que deram a ver, a milhares, aquilo que seus portadores não queriam acreditar. Por detrás dos óculos estão olhos que viram o preconceito em seu mais alto nível e que, sem condições de fechá-los, cegaram- 
se um pouco deixando suas lentes nas mãos dos soldados da SS. Os edredons, por sua vez, perderam sua serventia. Em invernos gélidos, o que restara aos prisioneiros foram os farrapos de pano fino. Braços e pernas falsas iriam ser o suporte de outrem, seus donos provavelmente perderam a vida por não serem mais aptos aos trabalhos pesados. Nunca se saberá a quem pertenciam os sapatos, as roupas, as malas encontradas no "Canadá". Há simplesmente a "impossibilidade de se esgotar a pluralidade de referências que circunda culturalmente cada "objeto" apresentado" (Maciel 2004: 23).

Esses objetos mortos, por não serem mais o que eram quando seus donos (também mortos) os adquiriram, parecem ter perdido seu valor primevo. Eles podem ser ressignificados, outros donos aparecerão e farão uso muito pessoal de cada um deles, mas aquele momento primordial, o momento do primeiro uso, nunca mais retornará. Os objetos também foram mortos, simbolicamente, juntamente com seus donos nos campos de Auschwitz. Eva testemunha seu choque ao ver as pilhas de coisas; parece que a autora não consegue deixar de encarar os objetos e associá-los a seus donos. Essa "pluralidade de referências" sugere que uma associação intrínseca entre as coisas e seus proprietários seja inevitável.

Em uma área estavam malas de crianças, a maioria com nomes e datas de nascimento que os pais haviam cuidadosamente escrito na parte da frente. Outro cômodo guardava centenas de carrinhos de bebê vazios, como uma sala de espera perpétua da qual nenhuma criança retornava. (Schloss 2013: 115)

As crianças que foram enviadas a Auschwitz perderam sua infância. Aquilo que Eva reconheceu como sendo um gesto de carinho e cuidado dos pais - o nome dos filhos escrito cuidadosamente nas malas - agora faz parte de um acervo do vazio. $\mathrm{O}$ vazio das malas, o vazio dos carrinhos de bebês, o vazio da infância. Pode-se pensar que esses objetos são testemunhas de meninices interrompidas, dos elos parentais quebrados. Como diz a autora, "nenhuma criança retornava" da sala vazia, não há criança nos carrinhos ou à espera de sua mala. As coisas deixadas nesse armazém testemunham o que já foi, e não mais o é.

E é sob esse prisma que, ao serem incorporados pela nossa vida - seja porque são possuídos, seja porque entram no mundo de nossas referências particulares - eles ganham um outro estatuto, configurando-se como uma presença que testemunha nossa presença ativa. (Maciel 2004: 103)

No caso do trecho relatado por Eva, os objetos parecem ter sido incorporados à memória para testemunhar a "presença ativa" das crianças que os possuíram. Assim como olhar para a subjetividade dessas coisas, e observar que elas mostram o amor dos pais pelos filhos. Estes tinham um nome antes de chegar ao campo, ele estampava a parte da frente das malas. Entretanto, esses objetos agora servirão a outros. Segundo Eva, o "Canadá" tinha como propósito 
saquear as posses dos judeus e enviá-las de volta para a Alemanha, onde elas seriam distribuídas as pessoas comuns e as famílias dos soldados. "Os homens alemães faziam a barba com lâminas de judeus enquanto as boas mães alemãs empurravam carrinhos de bebê de judeus, e os avós usavam óculos de judeus para ler os relatos sobre os esforços de guerra nos jornais" (Schloss 2013: 115).

Os objetos, em suas múltiplas possibilidades de referência e reutilização, possuem a capacidade de migrar. Se antes os óculos pertenciam a um judeu, assassinado nas câmaras de gás, agora sustenta a visão de um cidadão nazista que acompanha a guerra pelos jornais, longe dos horrores dos campos de concentração. Contudo, o ato de migrar não apaga sua significação primeira. Os óculos nazistas já foram óculos judeus. Os carrinhos de bebê que são empurrados pelas mães alemãs, fizeram parte do cotidiano de mães judias, órfãs de filhos. As coisas migratórias, por assim dizer, guardam seu passado e parecem testemunhar o inenarrável. Elas lutam por sua sobrevivência através da memória. Maria Esther Maciel (2004: 102) cita Carlos Drummond de Andrade, refletindo acerca da importância da presença das coisas: “O que seria delas sem o apelo à existência?". Ao migrar, as coisas continuam existindo, elas mantêm sua função. $\mathrm{O}$ que resta é apelar à sobrevivência de seu significado e de sua memória, algo que a literatura parece viabilizar.

Preservar a memória, salvar os restos, o passado, as falas e as imagens para não esquecer. Inventando uma estratégia de conservação, sem sacralizar fatos, a literatura pode dar esse testemunho de um trauma que influencia inconscientemente a vida da Europa contemporânea. (Casa Nova 2014: 68)

A memória das vítimas do "holocausto" sugere sua presença através dos objetos que possuíram. Passado, família e vida social estariam refletidas também nas imagens das pilhas de coisas no "Canadá". O testemunho de Eva seria, portanto, o espelho do trauma que influencia, até nos dias de hoje, a vida do mundo contemporâneo. Em "Depois de Auschwitz", a autora escreve que nada era desperdiçado. Até mesmo as mechas de cabelos raspados eram reutilizadas pelos nazistas, que as transformavam em carpetes e meias. Aqui, nota-se que nem sempre as "coisas migratórias" receberão a mesma função de outrora. Talvez a capacidade de migrar caminhe lado a lado com a capacidade de se disfarçar, isso porque os cabelos ainda pertencerão às prisioneiras judias mesmo que transformados em algo diferente do original. Ali estarão sempre presentes, de forma imperceptível, marcas de uma feminilidade que se perdeu em um campo de concentração.

Naquela primeira manhã, fui colocada para trabalhar no Canadá pegando roupas e casacos e procurando por "tesouros" escondidos - e fiquei inocentemente surpresa com o que encontrei. As pessoas escondiam dinheiro e joias, mas também comida, relógios, documentos e quaisquer outros itens, incluindo talheres, provavelmente pensando que eles seriam úteis. (Schloss 2013: 117) 
Os soldados da SS buscavam por "tesouros", algo com que pudessem obter algum tipo de lucro. Em algum momento de seu testemunho, Eva afirma que os saques e a corrupção eram atos presentes e constantes na vida do campo. Esperando encontrar esses objetos de tanto valor para os soldados, a autora encontrou, afinal, a ânsia pela sobrevivência que aqueles itens refletiam. Os prisioneiros haviam levado consigo tudo o que pudesse garantir sua subsistência em Auschwitz, sem saber que, posteriormente, nada lhes restaria. Os que lhes parecia útil fora dos portões, perdera sua identidade. Figuram como "objetos mortos", que por sua existência latente, impedem sua descrição. Retorna-se à "impossibilidade de autenticidade" de Agamben, na qual as coisas deixam de ter o mesmo significado do passado quando enfrentam a realidade nua do campo.

Mais adiante, Eva descreve suas singelas descobertas com relação às coisas que encontrava no "Canadá". Enquanto a SS via como "tesouros" as joias, o dinheiro, os relógios e o ouro dos prisioneiros, a autora notou que esses itens nada importavam às vítimas recém-chegadas. A liberdade e a vida junto à família parecem constituir a verdadeira riqueza para aqueles que jamais se reencontrariam. Apenas o texto escrito por Eva, e por outros sobreviventes, poderia ser capaz de fazer ressurgir o amor em forma dos objetos deixados em Auschwitz. Segundo Maciel (2004: 97), “[...] a linguagem tem a dupla (e contraditória) potencialidade de restituir a presença das coisas ao mesmo tempo em que as faz desaparecer enquanto realidade bruta."

Às vezes, os "tesouros" que eu encontrava não eram nada mais do que fotografias de família, cuidadosamente cortadas e dobradas - uma pequena foto de um bebê sorridente, ou um antigo retrato dos pais de alguém, costurada nas linhas de uma jaqueta. (Schloss 2013: 117)

Uma vez mais um objeto representa a separação. A fotografia poderia ser compreendida, nesse caso, como um "objeto morto" que, em sua contradição, reflete sobre si mesmo a vida. Talvez ela pudesse revelar, de forma mais direta e visível, a memória presente da vida e da morte dos prisioneiros do campo. Um bebê que nunca mais dormirá no carrinho que foi enviado à Alemanha, fotografias que imortalizaram momentos restantes apenas na memória do próprio objeto - já que os personagens daqueles tempos não mais existem.

Fiquei encarando uma fotografia de uma mãe e um pai segurando seu filho pequeno e percebi, com absoluto terror, que aquilo era a única coisa que importava para quem a tinha escondido - e que nenhuma daquelas pessoas voltaria a se encontrar. Todas estavam mortas. (Schloss 2013: 117)

Segundo Casa Nova (2014: 68), as fotos seriam "como testemunhas do sofrimento reduzidas agora ao silêncio." Para muitas famílias, a fotografia de um ente querido seria a única lembrança dos momentos felizes antes do inferno. $\mathrm{O}$ sofrimento reduzido ao silêncio sugere que o testemunho poderia dar voz, mesmo que rouca, àqueles que não puderam se expressar. Como já mencionado, 
o testemunho nunca poderá ser completo, essencial. A família da foto está morta. Assim como os donos dos óculos, das malas, dos carrinhos de bebê, dos sapatos, dos cabelos transformados em carpetes. Mas, conforme Agamben (2008: 36), "o sobrevivente tem a vocação da memória, não pode deixar de recordar."

Eva definiu o "Canadá" como "nada além de um macabro cemitério de bens materiais" (Schloss 2013: 117). Ao libertar-se de Auschwitz-Birkenau, juntamente com sua mãe em 1945, a autora percebeu que não apenas aqueles armazéns imensos conservavam a tristeza e a dor por meio das coisas - pertences que pertencem à história (de vida e do mundo). Sua própria vida seria afetada pelos objetos, e as lembranças de um tempo passado bateriam à porta. No caminho para Auschwitz, dentro dos vagões de gado, Heinz confessou à sua irmã que havia escondido algumas de suas pinturas na última casa onde se escondera com seu pai. “- Elas estão debaixo das placas do chão, perto da janela do sótão. Se eu não voltar, foi lá que eu as escondi" (Schloss 2013: 99).

Ao voltar para Amsterdã, Eva encheu-se de uma coragem relutante e chegou ao endereço do esconderijo do irmão. Seu pai, que morrera de forma desconhecida em Auschwitz, era uma figura constante em seus pensamentos. Testemunhar em seu livro cada passo, da saída do campo até esse momento de reencontro com o irmão ausente através da memória, parece algo que liga o movimento do testemunho com o passado e com o presente. De acordo com Casa Nova (2014: 69) "as pequenas coisas do testemunho testemunham o movimento do tempo $[\ldots]$ ". Tempos que se encontrarão novamente por intermédio da memória contida em cada objeto que será localizado na antiga residência da Sra. Katee-Walda.

\footnotetext{
Não sei dizer se eu esperava realmente encontrar alguma coisa, mas quando levantamos as tábuas e olhamos para baixo, vimos algumas telas planas. Enfiei minha mão no buraco e peguei um quadro, depois outro, e depois outro, e os coloquei sobre o chão. Mutti os pegou com as mãos trêmulas e conseguimos ver toda a imaginação maravilhosa e o talento de Heinz diante dos nossos olhos. (Schloss 2013: 179)
}

Como quem escava as memórias, Eva e Mutti encontraram os quadros que Heinz e Pappy haviam pintado. Os objetos-quadros parecem carregar em si todo o peso de uma vida feliz enquanto família, mas, ao mesmo tempo, refletem o presente carregado de vazios. Talvez as pinturas possam dizer algo sobre os dois homens da família. Eva, por exemplo, afirma que Heinz possuía imaginação e talento incríveis. Entretanto, agora, o corpo que pintara não tem mais mãos ou criatividade. Seria como dizer que só resta a ele uma voz muda, representada por cada quadro e cada objeto que lhe pertenceu. Isso sugere que não há texto ou testemunho que possa preencher os espaços do que não existe mais, mesmo que ele nasça para descrever essas lacunas.

Talvez cada palavra, cada escritura nasce, nesse sentido, como testemunho. E, por isso mesmo, aquilo de que dá testemunho não pode ser já língua, já escritura: pode ser somente um não-testemunhado. Isso é o som que provém da lacuna, a não-língua que se fala 
sozinho, de que a língua responde, em que nasce a língua. E é sobre a natureza deste nãotestemunhado, sobre a não-língua que é preciso interrogar-se. (Agamben 2008: 47)

A "não-língua", a ausência do irmão pintor, do pai provedor e de tantos outros pais e irmãos não poderá ser suprida pelo testemunho, e nem ao menos pelos objetos que rememoram seus momentos em vida. Dos 24 quadros de Heinz e 10 de seu pai, restou a Eva apenas testemunhar esse período sem normas. A importância desses e de outros objetos ao longo da obra parece sugerir algo que foi referido por Maria Esther Maciel (2004: 103), quando esta faz uma menção a uma frase de Rainer Maria Rilke: “As coisas, só elas, falam”. As coisas seriam, nesse contexto, "a não-língua que se fala sozinho" e que é preciso interrogar. As pinturas falam, à sua maneira, o que Heinz (e outras tantas vítimas) esperavam e sentiam no momento em que nada segue a ordem social do respeito.

Uma pintura em especial fez com que eu ficasse com os olhos marejados, e eu tive de me conter. Heinz havia pintado a si mesmo estudando em sua escrivaninha, com o calendário na parede marcando o dia 11 de maio, meu aniversário. Partiu o meu coração saber que ele pensava em mim, assim como eu pensava nele. (Schloss 2013: 180)

Os sonhos do garoto que adorava ler foram interrompidos. Os desenhos do quadro acima mencionado revelam o desejo de levar uma vida normal e de reencontrar a irmã. Tantos pensamentos não ditos e situações não vividas que só foram interpretadas por meio de uma única pintura em especial. "Assim, a impossibilidade de testemunhar, a "lacuna" que constitui a língua humana, desaba sobre si mesma para dar lugar a uma outra impossibilidade de testemunhar - a daquilo que não tem língua" (Agamben 2008: 48). Como testemunhar as esperanças e sofrimentos do irmão? Como dar voz àquele que só se faz presente na memória, de Eva, de sua mãe e de seus quadros? A materialidade das coisas pode não ser suficiente para testemunhar eventos tão significantes como o "holocausto". Contudo, o fato de ainda resistirem ao tempo através das experiências de todos aqueles que resolveram testemunhar, parecem comprovar que os objetos são impregnados com as marcas da memória.

Nesse caso, a experiência e a memória têm como registro a exterioridade sensível de tudo o que materialmente as define e as consome, como se só as coisas pudessem perdurar para além de nosso esquecimento e nossa precariedade. (Maciel 2004: 14)

\section{Algumas CONSIDERAÇÕES}

Tratar de assuntos tão complexos, como os horrores testemunhados do "holocausto", não é tarefa fácil. Por intermédio de uma linguagem simples que expressa sentimentos profundos, Eva Schloss pôde exteriorizar aquilo que, por muitos anos, esteve guardado nos fundos da memória. Relembrar a infância, os esconderijos, a ida para o campo de concentração e, posteriormente, a dificuldade em se adaptar ao "mundo real" do pós-guerra parece ter contribuído para o 
surgimento de duas linhas de forças opostas. Por um lado, surge a necessidade de narrar, de contar, de testemunhar. O que houve não deve mais acontecer. Por outro lado, há a lembrança que machuca, a falta da proteção do pai, a ausência do amor do irmão.

Esses sentimentos contraditórios sugerem que, para testemunhar, seja necessário dar voz àqueles que não possuem mais o dom da fala. Heinz e Pappy não vivem mais em matéria, mas em memória. Memória esta que parece estar refletida tanto nos quadros encontrados por Eva e sua mãe, quanto nos milhares de objetos do "Canadá" que pertenceram a tantos outros pais e irmãos. Os objetos mortos dos armazéns retratam a vida morta. Entretanto, apesar da autora não sentir pelos donos dos objetos o mesmo que sente por seu irmão e seu pai, parece plausível apontar que as coisas lá encontradas são parte de um todo que auxilia na preservação de uma memória nunca experienciada. Em outras palavras, Eva não guarda os rostos, os gestos e a personalidade de cada prisioneiro que teve seus bens saqueados. Mas ao revirar a pilha de seus objetos pessoais, essa memória nunca experienciada, que corresponde à vida de cada um deles com a qual Eva nunca teve contato, sugere uma aproximação entre vida e morte.

Os donos dos objetos, os pais que escreveram o nome do filho nas malas amontoadas, não vivem mais. Morte. Contudo, essas mesmas malas os aproximam de algo que se assemelha à vida. Eles estão vivos, de certa forma, por meio dos objetos que deixaram para trás. Os objetos mortos representariam uma vida que foi, mas que não é mais. O que resta são as lembranças de Eva, memórias de objetos que caracterizam a presença de seus possuidores. Vida. Essas são reflexões iniciais que pretenderam indagar qual o papel da imensidão de coisas empilhadas em Auschwitz-Birkenau no que se refere à memória. Como afirmou Agamben, as verdadeiras testemunhas não podem mais testemunhar pois estão mortas. O calar de suas vozes parece não conseguir esconder os grandes significados que seus itens pessoais possuem. Por detrás da materialidade do carrinho de bebê reutilizado por uma mãe não judia, estaria a figura do bebê que outrora vivia feliz com seus pais, mas que agora configura-se numa testemunha sem vida.

\section{REFERÊNCIAS}

AgAmbeN, G. (2008), O que resta de Auschwitz: o arquivo e a testemunha, São Paulo, Boitempo.

CASA NOVA, V. (2014), “Cascas sobre o papel: memória do dilaceramento”, Aletria, 2, 6575.

CHADE, J. (2018), “O ódio de hoje lembra muito o dos anos 30”, Estadão [Consulta: 22 março 2018]. Disponível em: <http://internacional.estadao.com.br/noticias/geral,oodio-de-hoje-lembra-muito-o-dos-anos-30,70002176552>.

MACIEL, M. E. (2004), A memória das coisas: ensaios de literatura, cinema e artes plásticas, Rio de Janeiro, Lamparina. 
SCHLOSS, E. (2013), Depois de Auschwitz, São Paulo, Universo dos livros. (trad. de Amanda Moura).

(c)

Llevat que s'hi indiqui el contrari, els continguts d'aquesta revista estan subjectes a la llicència de Creative Commons: Reconeixement 3.0 Espanya. 